\title{
Research Paper: Comparison of Perfectionism and Tolerance of Ambiguity in the Subtypes of Illness Anxiety Disorder
}

Berivan Moloudi ${ }^{1}$ (i), Ali Khademi ${ }^{1^{*}}$ (])

1. Department of Clinical Psychology, Faculty of Humanities, Urmia Branch, Islamic Azad University, Urmia, Iran.

\begin{tabular}{|c|c|}
\hline \multirow{2}{*}{$\begin{array}{l}\text { Use vour device toscan } \\
\text { and read the aricic online }\end{array}$} & \\
\hline & chtration Moloudi, B., \& Khademi, A. (2021). Comparison of Perfectionism and Tolerance of Ambiguity in the Subtypes of \\
\hline 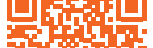 & Illness Anxiety Disorder. Journal of Practice in Clinical Psychology, 9(4), 303-312. https://doi.org/10.32598/jpcp.9.4.773.1 \\
\hline 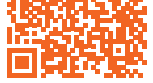 & doi'https://doi.org/10.32598/jpcp.9.4.773.1 \\
\hline
\end{tabular}

\section{(c) (1) (\$)}

Article info:

Received: 24 Apr 2021

Accepted: 19 Sep 2021

Available Online: 01 Oct 2021

Keywords:

Perfectionism, Anxiety disorders, Hypochondriasis

\section{ABSTRACT}

Objective: Illness Anxiety Disorder (IAD) has two subtypes, care-seeking type, and careavoidant. There is little information about the differences between the two subtypes.

Methods: This study was carried out to compare perfectionism and tolerance of ambiguity in the subtypes of the IAD. To this end, a causal-comparative design was employed. The statistical population of the study included clients with symptoms of IAD who were referred to psychiatric and psychological clinics in Urmia city (West Azerbaijan Province, Iran) in 2019. After conducting a semi-structured interview, 60 subjects were selected as samples, using a convenience sampling method. The Perfectionism Inventory and the Tolerance of Ambiguity questionnaire were utilized for data collection. The collected data were analyzed by the multivariate analysis of variance test.

Results: The care-avoiding subtype showed significantly higher scores on some subscales of perfectionism, including concern over mistakes $(\mathrm{F}=8.735 ; \mathrm{P}=0.005)$, need for approval $(\mathrm{F}=4.988$; $\mathrm{P}=0.029)$, and organization $(\mathrm{F}=4.505 ; \mathrm{P}=0.038)$. On the contrary, the care-seeking type showed a significantly lower tolerance of ambiguity than the care-avoidant type $(\mathrm{t}=2.689 ; \mathrm{P}=0.001)$.

Conclusion: The findings of this study suggest some subtle differences between the subtypes of IAD. As a result, paying attention to these differences can lead to developing tailored treatments for each of the IAD subtypes.

\footnotetext{
* Corresponding Author:

Ali Khademi, PhD.

Address: Department of Clinical Psychology, Faculty of Humanities, Urmia Branch, Islamic Azad University, Urmia, Iran.

Tel: +98 (44) 31803000

E-mail: clinicalpsy8@gmail.com
} 


\section{Highlights}

- Care-seeking and care-avoidant subjects are not perfectionists equally.

- Accordingly, care-avoiding subjects are more perfectionist in concern over mistakes, need for approval, and organization.

- Care-seeking and care-avoidant subjects do not tolerate ambiguity equally.

- Accordingly, care-avoidant subjects have a higher tolerance of ambiguity than care-avoidant subjects.

\section{Plain Language Summary}

Many people suffer from Illness Anxiety Disorder (IAD). They have excessive fears of having or acquiring severe disease (s). They fall into one of the two subtypes of the disorder: care-seeking or care-avoidant. These subtypes may differ in some essential psychological variables. Identifying such variables can help researchers determine the cause of some behaviors, such as care-seeking or care-avoiding. Hence, in this study, two essential psychological variables, i.e., perfectionism and tolerance of ambiguity, were compared between the two subtypes of the disorder. As expected, the two sub-types had significant differences in terms of perfectionism and tolerance of ambiguity.

\section{Introduction}

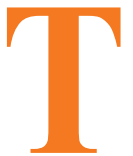

he main diagnostic criteria of a disorder, now known as "Illness Anxiety Disorder" (IAD), are excessive fears of having or acquiring severe disease(s), high health anxiety, and behavioral symptoms, such as repeated body checking (Newby, Hobbs, Mahoney, Wong, \& Andrews, 2017). This disorder can interfere with social functioning (Reuman, Jacoby, Blakey, Riemann, Leonard, \& Abramowitz, 2017) and cause considerable personal distress (Arnáez, García-Soriano, G., López-Santiago, \& Belloch, 2020; Reuman et al., 2017). Those living with the disorder usually catastrophize the misinterpretation of harmless bodily sensations. The presence of a benign physical condition or a previous health issue that is no longer active is also considered very dangerous by persons with the disorder (Reuman et al., 2017). The overall prevalence rate of IAD is estimated at 4-6\% and affects both sexes equally (Reuman et al., 2017). Regardless of the serious concerns of those individuals having IAD, the way they react to the disorder can be somehow different (Reuman et al., 2017). Accordingly, some individuals turn to medical care to allay their concerns, while others refuse to seek medical care. Hence, patients can be classified as either "care-seeking" subtype or "care-avoidant" (APA, 2013; Newby et al., 2017). In the former group, medical care, including physician visits or undergoing medical tests and procedures, is frequently used, whereas, in the latter group, medical care is rarely used (APA, 2013; Arnáez et al., 2020). At this point, a fundamental question arises: why some persons with IAD seek treatment while others avoid it? Undoubtedly, many differences in people's behavior can be traced to their personality characteristics (Letzring, 2008), and care-seeking or care-avoidance cannot be an exception to this rule. In this regard, perfectionism (Kamushadze, Martskvishvili, Mestvirishvili, \& Odilavadze, 2021; Rosenbloom \& Eldror, 2017; Seeliger \& Harendza, 2017) and tolerance of ambiguity (Abbasnia, Sangani, Donyavi, Abbasniya, Rezaeefard, \& Moosavi, 2019; Arnáez et al., 2020) are essential personality characteristics, which can be involved in behaviors, such as care-seeking or care-avoidance.

Perfectionism is a variable whose role in mental health has been repeatedly verified (Frost, Marten, Lahart, \& Rosenblate, 1990; Frost \& Marten, 1990; Mitchell, Newall, Broeren, \& Hudson, 2013; Soidla \& Akkermann, 2020). It can be potentially related to the issue of care-seeking or avoidance, as well. As Stoeber and Childs (2011) reported, patients seeking treatment for anxiety and depression frequently exhibit high levels of perfectionism. It means high levels of perfectionism that can motivate persons to seek treatment. Similarly, the same reasoning could be valid for IAD. According to previous studies, perfectionism is a personality trait that plays a crucial role in Somatic Symptoms and Related Disorders (SSRD) (Williams, Zahka, \& Kullgren, 2020). The relationship between perfectionism and IAD (Arnáez et al., 2020; Koven \& Abry, 2015) and some other disorders belonged to this category, such as somatic symptoms (Willis \& Chalder, 2021) and conversion disorders (Caulley, Kohlert, Gandy, Olds, \& Bromwich, 
2018), has also been observed. In general, people with negative perfectionism have a strong desire to be perfect, have an all-or-nothing mindset, and obey unrealistic high standards (Luyten, Kempke, Van Wambeke, Claes, Blatt, \& Van Houdenhove, 2011). Hence, it can be hypothesized that if a person has high levels of perfectionism, they are likely to expect maximum physical and mental health, and such an expectation even makes them incapable of ignoring the slightest sign of their bodily dysfunction (Letzring, 2008).

Another variable that may distinguish between the subtypes of IAD is tolerance of ambiguity (Carleton, Weeks, Howell, Asmundson, Antony, \& McCabe, 2011). Difficulties in tolerating ambiguity may contribute to health anxiety (Fergus, Bardeen, \& Orcutt, 2015). Tolerance of ambiguity describes an individual's perception of uncertain situations (Gärtner, Bußenius, Prediger, Vogel, \& Harendza, 2020) or the tendency to perceive ambiguous situations as desirable (McLain, Kefallonitis, \& Armani, 2015). Many studies have shown that low levels of tolerance of ambiguity are highly correlated with various mental disorders, and conversely, higher levels are associated with better psychological well-being (Bledsoe, 2011; Hancock \& Mattick, 2020). Higher intolerance of uncertainty and anxious symptoms mediated the relationship between loneliness and hypochondriasis disorder (the last name of IAD) (Barnett, Moore, \& Archuleta, 2019). Arnáez et al. (2020) believe that intolerance of ambiguity as one of the illness-related Intrusive Thoughts (illness-ITs) generates many dysfunctional, emotional, cognitive, and behavioral consequences for a person with illness anxiety disorder. Carleton et al. (2011) believes that measuring ambiguity is critical in anxiety disorders because the feeling of indecision caused by anxiety forces the person to engage in various behaviors (either seeking or avoiding treatment).

As noted, although previous research has relatively examined the role of perfectionism (Arnáez et al., 2020; Koven \& Abry, 2015) and tolerance of ambiguity (Arnáez et al., 2020; Barnett et al., 2019; Fergus et al., 2015) in IAD, the subtypes of this disorder have not yet been addressed. Knowing the difference between the subtypes of this disorder in terms of the degree of perfectionism or the ability to tolerate ambiguity is of paramount importance because it can help develop specific treatment programs for each subtype. Attention to the subtypes of the disorder is the distinguishing feature of this research from previous researches. Therefore, this study aimed to compare perfectionism and tolerance of ambiguity in the subtypes of IAD to expand the existing theoretical knowledge and also answer two questions: 1)
Is there a significant difference in the subscales of perfectionism (i.e., concern over mistakes, high standards for others, need for approval, organization, perceived parenting pressure, planfulness, rumination, and struggle for excellence) between care-seeking and care-avoidant subjects? and 2) Are care-seeking and care-avoidant subjects significantly different in the tolerance of ambiguity?

\section{Materials and Methods}

\section{Research design and participants}

This study used a causal-comparative design. The statistical population of the study was clients with symptoms of IAD who were referred to psychiatric and psychological clinics in Urmia city (2019). The study used a convenience sampling method. To perform sampling, a psychiatrist carefully interviewed patients suspected of having the disorder according to the DSM-5 diagnostic criteria for the IAD at first. Afterward, as recommended by statisticians (Delavar, 2020), 60 eligible subjects were selected as sample members, considering the design of the study. Finally, after justifying the importance of the research, the questionnaires were delivered to the subjects.

The average number of monthly referrals to physicians/ medical centers was used to differentiate between careseeking and care-avoidant subjects. If a patient had more visits than expected in the last six months (i.e., at least two visits per month) due to an imagined disease for which medical evidence had not been confirmed, they were assigned to the care-seeking group. In contrast, severe anxiety about a supposed disease combined with a typical number of referrals (up to once a month) was considered for allocation of the individual to the care-avoidant group. The reason for establishing such a criterion is that care-avoidant subjects are thought to be afraid that referrals to physicians/medical centers will eventually reveal the disease about which they are concerned. As a result, the number of their referrals is significantly lower than that of their care-seeking counterparts (Higgins-Chen, Abdallah, Dwyer, Kaye, Angarita, \& Bloch, 2019). Inclusion criteria included a diagnosis of IAD based on DSM-5 and being interested in participating in the study. Not having enough literacy to read and understand questions and having chronic physical illnesses or other psychiatric disorders were the exclusion criteria.

To observe ethical considerations, participation in the study was completely arbitrary, and the subjects could withdraw from the study at any time they wished. Furthermore, informed consent was obtained from the participants, and the questionnaires were also unnamed and coded to ensure that the subjects answered correctly and freely. The study 
process was as follows: after completing the questionnaires by the participants, the collected data were analyzed using SPSS software, v. 22, MANOVA, and independent t-tests.

\section{Study instruments}

\section{Perfectionism Inventory (PI)}

The Perfectionism Inventory (PI) was prepared by Hill, Huelsman, Furr, Kibler, Vicente, and Kennedy (2004) and contains 59 items. Participants must specify the amount of each sentence describing them in a range of five options, from agree to disagree (Hill et al., 2004). The subscales of the instrument are concern over mistakes (range of scores: 8-40), high standards for others (range of scores: 7-35), need for approval (range of scores: 8-40), organization (range of scores: 8-40), perceived parenting pressure (range of scores: 8-40), planfulness (range of scores: 7-35), rumination (range of scores: 7-35), and struggle for excellence (range of scores: 6-30) (Hill et al., 2004). Gäde, Schermelleh-Engel, and Klein (2017), calculated the correlations of the subscales of this instrument with that of the Multidimensional Perfectionism Scale (MPS). The results confirmed the validity of the instrument (the Cronbach's alpha coefficients of the subscales ranged between 0.81 and 0.95 ).
In a similar study conducted in Iran, the calculated Cronbach's alpha coefficient was satisfactory $(\alpha=0.92)$, which shows a proper internal consistency for the instrument (Sharifi, Salehi, EmamiPour, \& Bashardoust 2015). The convergent validity of this instrument was measured by calculating its correlation coefficient with the Frost Perfectionism Questionnaire, which obtained a satisfactory result of 0.741 (Taghavizade Ardakani, Akbari, Hossein Khanzade, \& Moshkbide Haghighi, 2019).

\section{Tolerance of Ambiguity Questionnaire}

This questionnaire was developed by McLain (1993) and contains 22 items. It is scored on a 5-point Likert scale (from agree to disagree). The range of scores is between 20 and 110, where higher scores indicating lower levers of tolerance of ambiguity (McLain, 2009). They reported its reliability coefficient to be 0.82 (McLain, 2009). The Persian version of the questionnaire has acceptable psychometric properties (Aalipour, Abbasi, \& Mirderikvand, 2018). For instance, in a study, the reliability coefficient of the instrument using Cronbach's alpha coefficient was reported to be 0.85 , and its calculated validity through assessing structural validity was reported to be 0.48 (Fezi, Mahbobi, Zare, H., \& Mostafaei, 2012). Also, in another Iranian study, the face valid-

Table 1. Descriptive statistics of research variables $(\mathrm{N}=60)$

\begin{tabular}{|c|c|c|c|c|c|c|}
\hline Variables & Subtype & Mean $\pm S D$ & Minimum & Maximum & Skewness & Kurtosis \\
\hline \multirow{2}{*}{ Concern over mistakes } & Care-seeking & $17.16 \pm 4.93$ & 12 & 32 & 1.959 & 1.610 \\
\hline & Care-avoidant & $21.66 \pm 6.72$ & 11 & 39 & 0.411 & -0.059 \\
\hline \multirow{2}{*}{ High standards for others } & Care-seeking & $15.36 \pm 3.66$ & 11 & 25 & 1.233 & 0.797 \\
\hline & Care-avoidant & $17.26 \pm 5.25$ & 2 & 30 & -0.250 & 1.925 \\
\hline \multirow{2}{*}{ Need for approval } & Care-seeking & $16.63 \pm 4.75$ & 11 & 30 & 1.540 & 1.763 \\
\hline & Care-avoidant & $19.96 \pm 6.64$ & 11 & 36 & 0.506 & -0.765 \\
\hline \multirow{2}{*}{ Organization } & Care-seeking & $15.40 \pm 3.23$ & 9 & 25 & 1.207 & 1.253 \\
\hline & Care-avoidant & $18.10 \pm 6.17$ & 10 & 33 & 0.927 & 0.393 \\
\hline \multirow{2}{*}{ Perceived parenting pressure } & Care-seeking & $16.6 \pm 5.80$ & 11 & 28 & 0.988 & 0.759 \\
\hline & Care-avoidant & $17.1 \pm 5.33$ & 9 & 36 & 0.589 & -0.175 \\
\hline \multirow{2}{*}{ Planfulness } & Care-seeking & $13.96 \pm 2.87$ & 10 & 25 & 1.247 & 1.126 \\
\hline & Care-avoidant & $15.16 \pm 4.60$ & 10 & 26 & 1.396 & 1.021 \\
\hline \multirow{2}{*}{ Rumination } & Care-seeking & $13.93 \pm 3.11$ & 9 & 22 & 0.688 & 0.857 \\
\hline & Care-avoidant & $16.0 \pm 5.36$ & 8 & 28 & 0.395 & -0.809 \\
\hline \multirow{2}{*}{ Struggle for excellence } & Care-seeking & $12.53 \pm 3.45$ & 8 & 21 & 1.217 & 0.979 \\
\hline & Care-avoidant & $12.20 \pm 4.40$ & 7 & 27 & 1.718 & 1.519 \\
\hline \multirow{2}{*}{ Tolerance of Ambiguity (total score) } & Care-seeking & $65.53 \pm 5.19$ & 47 & 73 & -1.566 & 1.345 \\
\hline & Care-avoidant & $59.36 \pm 11.43$ & 35 & 78 & -0.479 & -0.336 \\
\hline
\end{tabular}


Table 2. Results of significance test for the Multivariate Analysis of Variance (MANOVA)

\begin{tabular}{|c|c|c|c|c|c|c|}
\hline Partial Etta Squared & Sig. & Error df & Hypothesis df & $\mathbf{F}$ & Value & Test \\
\hline 0.315 & 0.004 & 52 & 7 & 3.417 & 0.685 & Wilk's Lambda \\
\hline
\end{tabular}

Table 3. Results of multivariate analysis of variance test to compare perfectionism in the subtypes of IAD

\begin{tabular}{|c|c|c|c|c|c|}
\hline Variable & Sum of Squares & df & Mean Square & $\mathbf{F}$ & Sig. \\
\hline Concern over mistakes & 303.750 & 1 & 303.750 & 8.735 & 0.005 \\
\hline High standards for others & 54.150 & 1 & 54.150 & 2.637 & 0.110 \\
\hline Need for approval & 166.667 & 1 & 166.667 & 4.988 & 0.029 \\
\hline Organization & 109.350 & 1 & 109.350 & 4.505 & 0.038 \\
\hline Perceived parenting pressure & 99.80 & 1 & 99.80 & 1.610 & 0.211 \\
\hline Planfulness & 21.600 & 1 & 21.600 & 1.468 & 0.231 \\
\hline Rumination & 64.067 & 1 & 64.067 & 3.324 & 0.073 \\
\hline Struggle for excellence & 1.667 & 1 & 1.667 & 0.106 & 0.745 \\
\hline
\end{tabular}

ity of this instrument was confirmed (Hasanpoor, Aghayousefi, Alipoor, \& Zamir, 2019).

\section{Results}

The present study consisted of 60 subjects with IAD, of whom 40 subjects $(66.7 \%)$ were female and $20(33.3 \%)$ subjects were male. Also, 21 subjects (35\%) were single and 39 subjects $(65 \%)$ were married. In terms of subtypes of the disorder, 30 cases (50\%) were care-seeking and 30 cases $(50 \%)$ were care-avoidant. Table 1 shows descriptive statistics of the research variables.

To test the first hypothesis of the research, that is, the comparison of perfectionism in the subtypes of IAD, MANOVA was employed. Because in addition to the normal distribution of variables, the homogeneity of variance-covariance matrices is also a prerequisite for the MANOVA test, the Box's M test was used to ensure that the assumption was established. Given that the significance levels of this test were not statistically significant for any of the subscales of perfectionism $(\mathrm{P}>0.05)$, it was found that this assumption is valid. Table 2 shows the results of the significance test for the MANOVA.

As can be observed in Table 2, the result of the Wilks' lambda test was significant ( $\mathrm{F}=3.417$; $\mathrm{P}=0.004$; Wilks' lambda $=0.685$ ), meaning that the two subtypes of the IAD were different at least in one subscale of perfectionism. The significant subscales can be observed in Table 3 .

The results of testing the first hypothesis of the study are shown in Table 3. Based on the results of the eight subscales of perfectionism, the two subtypes of IAD were significantly different in the three subscales. These subscales were concern over mistakes $(\mathrm{F}=8.735 ; \mathrm{P}=0.005)$, need for approval $(\mathrm{F}=4.988 ; \mathrm{P}=0.029)$, and organization ( $\mathrm{F}=4.505 ; \mathrm{P}=0.038$ ).

An independent t-test also was used to test the second hypothesis of the study, i.e., the comparison of tolerance of ambiguity in the subtypes of IAD. Before that, the assumption of the normal distribution of variables was

Table 4. Results of independent t-test to compare the tolerance of ambiguity in the subtypes of IAD

\begin{tabular}{cccccccc}
\hline Groups & $\mathbf{N}$ & Mean \pm SD & t & df & Sig. & Mean Difference & Std. Error Mean \\
\hline Care-seeking & 30 & $65.53 \pm 5.19$ & & & & & \\
Care-avoidant & 30 & $59.36 \pm 11.43$ & & & & & \\
\hline
\end{tabular}


ensured by checking the skewness and kurtosis values and performing the Kolmogorov-Smirnov test $(\mathrm{P}>0.05)$.

As can be observed in Table 4, the result of the t-test was significant $(\mathrm{t}=2.689 ; \mathrm{P}=0.001)$, which means that there was a significant difference between tolerance of ambiguity in the two subtypes of IAD. Considering the mean scores of the two groups, it can be said that the care-seeking group had a lower tolerance of ambiguity than the care-avoidant group (the higher mean scores indicate a lower tolerance of ambiguity).

\section{Discussion}

This study was conducted to compare the two subtypes of IAD (i.e., care-seeking and care-avoidant) in perfectionism and tolerance of ambiguity variables. The results showed that the care-avoidant group had higher scores than the care-seeking group in some subscales of perfectionism. These subscales were concern about mistakes, the need for approval, and organization. This finding implies that at least in some aspects, the care-avoidant subtype is more perfectionist than the care-seeking subtype. Perfectionists are divided into two types of perfectionistic strivings and perfectionistic concerns (Hill, Huelsman, \& Araujo, 2010). Interestingly, the care-avoidant group in the present study was included in both types of perfectionism. They tend to achieve uncommonly high standards (perfectionistic strivings), and at the same time, perceive failures (perfectionistic concerns) (Hill et al., 2010; Johnson, 2019; Leung, Cloninger, Hong, Cloninger, \& Eley, 2019). It means that regardless of the type of perfectionism, care-avoidant groups are generally more perfectionist. Most researchers reported that higher levels of perfectionism are associated with more psychological problems (Gärtner et al., 2020; Johnson, 2019; Mitchell et al., 2013; Soidla \& Akkermann, 2020). Hence, we can expect a worse psychological condition in the care-avoidant subtype.

Because of their high perfectionism and their insatiable desire to eliminate all their health-related symptoms, the care-avoidant subjects do not seem to be satisfied with physicians' assurances about their healthy (Arnáez et al., 2020). As a result, they find seeking medical treatment futile, and as a result, their health condition worsens (Shumaker \& Rodebaugh, 2009). In this regard, Higgins-Chen et al. (2019) believed that each time a care-avoidant patient receives medical reassurance, this reassurance may reinforce their previous maladaptive thoughts about the ineffectiveness of medical care. Conversely, less perfectionism provides an opportunity for the extinction of maladaptive thoughts (ineffectiveness of medical care) and behaviors (care-avoiding) (Higgins-Chen et al., 2019). However, as far as we know, no other research has directly compared care-seeking and care-avoidant subtypes of IAD concerning the subscales of perfectionism. Other studies have only looked at the relationship between perfectionism and its comorbidity with other disorders, such as body dysmorphic disorder (Johnson, 2019), anxiety (Moroz \& Dunkley, 2019), depression (Moroz \& Dunkley, 2019), eating disorders (Soidla \& Akkermann, 2020), or IAD in general (Johnson, 2019). Therefore, due to the scarcity of research in this area, it is worthwhile for future research to examine and compare the level of psychological health in the subtypes of IAD, assuming that the psychological condition of the care-avoidant subtype is worse than that of the care-seeking subtype.

According to another finding of this study, the careseeking group had lower tolerance of ambiguity than the care-avoidant group. As of this writing, we did not find any other study comparing tolerance of ambiguity in the subtypes of IAD. However, the findings of this study are somewhat similar to those of Abbasnia et al. (2019). They compared tolerance of ambiguity in depressed, anxious, and normal subjects and observed that having disorders, such as depression and anxiety can reduce the persons' tolerance of ambiguity. They believe this happens due to some metacognitive problems that psychological disorders can cause, such as preoccupying the mind, providing a misjudgment of facts, and changing attitudes and expectations (Abbasnia et al., 2019). The same interpretation can be accepted about care-seeking persons.

We do not consider two possible explanations much far from the reality in this regard: 1) probably, care-seeking persons are less able to cope with the ambiguity and confusion caused by the IAD. Hence, they see seeking treatment as a coping strategy to reduce their ambiguity and confusion; 2) Another explanation relates to a concept called 'Health Locus of Control' (HLOC). According to this concept, a person who suffers from a physical/mental illness and believes that their health is beyond their control and depends on medical interventions has control over external health control and is more inclined to seek treatment (Ahmed, Salem, Saber, Abou Elazab, \& Atia, 2021; Skidmore, Dyson, Kupper, \& Calabrese, 2014). In contrast, a person who perceived a sense of control over their own health has control over internal health and is more inclined to avoid treatment (Ahmedet al., 2021; Pourhoseinzadeh, Gheibizadeh, \& Moradikalboland, 2017; Skidmore vet al., 2014). Therefore, it can be imagined that the care-seeking subtype can be categorized in the first category, and the care-seeking subtype 
can be categorized in the second category. The correctness of this hypothesis should be considered in future research.

\section{Conclusion}

The present study showed significant differences between the two subtypes of IAD in terms of perfectionism and the ability to tolerate ambiguity. Recognizing these differences can be effective both in the context of the factors involved in developing the disorder and in the development of specific therapies for each subtype of the disorder. Hence, considering the practical aspect of the research, therapists working with IAD patients are advised to pay more attention to reducing perfectionism when designing treatment intervention packages for patients of the care-avoidant subtype. In the case of patients of care-seeking subtype, however, the focus of treatment should be on increasing the tolerance of ambiguity.

\section{Limitations and suggestions}

The lack of rich research literature related to the comparison of the subtypes of IAD, as well as insufficient sample size, were of the most important limitations of this study, which made it difficult to interpret the results of the study. Although the present study provided evidence for studying subtypes of IAD, future studies need to test the validity of the findings of this study in larger samples. Designing intervention packages is also considered a valuable step towards the treatment of patients with IAD.

\section{Ethical Considerations}

\section{Compliance with ethical guidelines}

All ethical principles are considered in this article. The participants were informed about the purpose of the research and its implementation stages. They were also assured about the confidentiality of their information. They were free to leave the study whenever they wished, and if desired, the research results would be available to them.

\section{Funding}

This research did not receive any grant from funding agencies in the public, commercial, or non-profit sectors.

\section{Authors' contributions}

Both authors authors declared no conflict of interest.

\section{Conflict of interest}

The authors declare no conflict of interests.

\section{References}

Aalipour, K., Abbasi, M., \& Mirderikvand, F. (2018). [The effect of teaching breath's thinking strategies on subjective wellbeing and tolerance of ambiguity among students (Persian)]. Journal of Education Strategic in Medical Science, 11(1), 1-7. http:/ / edcbmj.ir/article-1-1322-en.htm

Abbasnia, S., Sangani, A., Donyavi, R., Abbasniya, N., Rezaeefard, E., \& Moosavi, S. M. (2019). [Comparison of metacognitive beliefs and tolerance of ambiguity in depressed, anxious and normal people (Persian)]. Journal of Gorgan University of Medical Sciences, 21(1), 60-8. http:/ / goums.ac.ir/journal/article-1-3236-en.html

Ahmed, S. R. H., Salem, S. G., Saber, N. M., Abou Elazab, R. T. A., \& Atia, M. M. (2021). Effectiveness of nursing intervention on health locus of control and self-efficacy in women with gestational diabetes. Evidence-Based Nursing Research, 3(1), 12. [DOI:10.47104/ebnrojs3.v3i1.188]

American Psychiatric Association (APA). (2013). Desk Reference to the Diagnostic Criteria From DSM-5 ${ }^{\circledR}$. Washington, D.C. American Psychiatric Publishing. https:/ / www.google.com/ books/edition/Desk_Reference_to_the_Diagnostic_Criteri/

Arnáez, S., García-Soriano, G., López-Santiago, J., \& Belloch A. (2020). Illness-related intrusive thoughts and illness anxiety disorder. Psychology and Psychotherapy, 94(1), 63-80. [DOI:10.1111/papt.12267] [PMID]

Barnett, M. D., Moore, J. M., \& Archuleta, W. P. (2019). A loneliness model of hypochondriasis among older adults: The mediating role of intolerance of uncertainty and anxious symptoms. Archives of Gerontology and Geriatrics, 83, 86-90. [DOI:10.1016/j.archger.2019.03.027] [PMID]

Bledsoe, J. R. (2011). Tolerance of ambiguity and inductive vs. deductive preference across languages and proficiency levels at BYU: A correlational study [PhD. dissertation]. Provo: Brigham Young University. https://scholarsarchive.byu edu/cgi/viewcontent.cgi?article $=3656 \&$ context $=$ etd

Carleton, R. N., Weeks, J., Howell, A., Asmundson, G., Antony, M., \& McCabe, R. (2011). Assessing the latent structure of the intolerance of uncertainty construct: An initial taxometric analysis. Journal of Anxiety Disorders, 26(1), 150-7. [DOI:10.1016/j.janxdis.2011.10.006] [PMID]

Caulley, L., Kohlert, S., Gandy, H., Olds, J., \& Bromwich, M (2018). When symptoms don't fit: A case series of conversion disorder in the pediatric otolaryngology practice. Journal of Otolaryngology - Head \& Neck Surgery, 47(1), 39. [DOI:10.1186/ s40463-018-0286-7] [PMID] [PMCID]

Delavar, A. (2020). [Research methods in psychology and education (Persian)]. Tehran: Virayesh. http://opac.nlai.ir/opac-prod/ bibliographic/8546101

Fergus, T. A., Bardeen, J. R., \& Orcutt, H. K. (2015). Examining the specific facets of distress tolerance that are relevant to health anxiety. Journal of Cognitive Psychotherapy, 29(1), 32-44 [DOI:10.1891/0889-8391.29.1.32] [PMID]

Fezi, A., Mahbobi, T., Zare, H. \& Mostafaei, A. (2012). [The relationship among cognitive intelligence and tolerance for ambiguity with critical job of Payame-Noor University students (Persian)]. Journal of Research in Behavioural Sciences, 10(4), 276-84. https://www.sid.ir/en/Journal/ViewPaper. aspx?ID=339090 
Frost, R. O., Marten, P., Lahart, C., \& Rosenblate, R. (1990). The dimensions of perfectionism. Cognitive Therapy and Research, 14(5), 449-68. [DOI:10.1007/BF01172967]

Frost, R. O., \& Marten, P. A. (1990). Perfectionism and evaluative threat. Cognitive Therapy and Research, 14(6), 559-72. [DOI:10.1007/ BF01173364]

Gäde, J. C., Schermelleh-Engel, K., \& Klein, A. G. (2017). Disentangling the common variance of perfectionistic strivings and perfectionistic concerns: A bifactor model of perfectionism. Frontiers in Psychology, 8, 160. [DOI:10.3389/fpsyg.2017.00160] [PMID] [PMCID]

Gärtner, J., Bußenius, L., Prediger, S., Vogel, D., \& Harendza, S. (2020). Need for cognitive closure, tolerance for ambiguity, and perfectionism in medical school applicants. BMC Medical Education, 20(1), 132. [DOI:10.1186/s12909-020-02043-2] [PMID] [PMCID]

Hancock, J., \& Mattick, K. (2020). Tolerance of ambiguity and psychological well-being in medical training: A systematic review. Medical Education, 54(2), 125-37. [DOI:10.1111/medu.14031] [PMID] [PMCID]

Hasanpoor, P., Aghayousefi, A., Alipoor, A., \& Zamir, M. (2019). [Effectiveness of transdiagnostic treatment on ambiguity tolerance, executive functions (accuracy and time) and memory in patients with obsessive-compulsive disorder (Persian)]. Journal of Psychological Science, 17(71), 837-47. http:/ / psychologicalscience. ir/article-1-52-fa.htm

Higgins-Chen, A. T., Abdallah, S. B., Dwyer, J. B., Kaye, A. P., Angarita, G. A., \& Bloch, M. H. (2019). Severe illness anxiety treated by integrating inpatient psychotherapy with medical care and minimizing reassurance. Frontiers in Psychiatry, 10, 150 [DOI:10.3389/fpsyt.2019.00150] [PMID] [PMCID]

Hill, R. W., Huelsman, T. J., \& Araujo, G. (2010). Perfectionistic concerns suppress associations between perfectionistic strivings and positive life outcomes. Personality and Individual Differences, 48(5), 584-9. [DOI:10.1016/j.paid.2009.12.011]

Hill, R. W., Huelsman, T. J., Furr, R. M., Kibler, J., Vicente, B. B., \& Kennedy, C. (2004). A new measure of perfectionism: The perfectionism inventory. Journal of Personality Assessment, 82(1), 80-91 [DOI:10.1207/s15327752jpa8201_13] [PMID]

Johnson, S. (2019). The role of perfectionism and cognitive processing abnormalities in dysmorphic concern. [PhD. dissertation] Adelaide: Flinders University. https:/ flex.flinders.edu.au/file/ ff27d0c0-d0e9-4b12-b45b-933ed2037234/1/ThesisJohnson2019. pdf

Kamushadze, T., Martskvishvili, K., Mestvirishvili, M., \& Odilavadze, M. (2021). Does perfectionism lead to well-being? The role of flow and personality traits. Europe's Journal of Psychology, 17(2), 43-57. [DOI:10.5964/ejop.1987]

Koven, N. S., \& Abry, A. W. (2015). The clinical basis of orthorexia nervosa: Emerging perspectives. Neuropsychiatric Disease and Treatment, 11, 385-94. [DOI:10.2147/NDT.S61665] [PMID] [PMCID]

Letzring, T. D. (2008). The good judge of personality: Characteristics, behaviors, and observer accuracy. Journal of Research in Personality, 42(4), 914-32. [DOI:10.1016/j.jrp.2007.12.003] [PMID] [PMCID]

Leung, J., Cloninger, C. R., Hong, B. A., Cloninger, K. M., \& Eley, D. S. (2019). Temperament and character profiles of medical students associated with tolerance of ambiguity and perfectionism. PeerJ, 7, e7109. [DOI:10.7717/peer.7109] [PMID] [PMCID]
Luyten, P., Kempke, S., Van Wambeke, P., Claes, S., Blatt, S. J., \& Van Houdenhove, B. (2011). Self-critical perfectionism, stress generation, and stress sensitivity in patients with chronic fatigue syndrome: Relationship with severity of depression. Psychiatry, 74(1), 21-30. [DOI:10.1521/psyc.2011.74.1.21] [PMID]

McLain, D. L. (2009). Evidence of the properties of an ambiguity tolerance measure: The multiple stimulus types ambiguity tolerance scale-II (MSTAT-II). Psychological Reports, 105(3) 975-88. [DOI:10.2466/PR0.105.3.975-988] [PMID]

McLain, D. L., Kefallonitis, E., \& Armani, K. (2015). Ambiguity tolerance in organizations: Definitional clarification and perspectives on future research. Frontiers in Psychology, 6, 344. [DOI:10.3389/fpsyg.2015.00344] [PMID] [PMCID]

McLain, D. L. (1993). The MSTAT-I: A new measure of an individual's tolerance for ambiguity. Educational and Psychological Measurement, 53(1), 183-9. [DOI:10.1177/0013164493053001020]

Mitchell, J. H., Newall, C., Broeren, S., \& Hudson, J. L. (2013) The role of perfectionism in cognitive behaviour therapy outcomes for clinically anxious children. Behaviour Research and Therapy, 51(9), 547-54. [DOI:10.1016/j.brat.2013.05.015] [PMID]

Moroz, M., \& Dunkley, D. M. (2019). Self-critical perfectionism, experiential avoidance, and depressive and anxious symptoms over two years: A three-wave longitudinal study. Behaviour Research and Therapy, 112, 18-27. [DOI:10.1016/j. brat.2018.11.006] [PMID]

Newby, J. M., Hobbs, M. J., Mahoney, A. E., Wong, S. K., \& Andrews, G. (2017). DSM-5 illness anxiety disorder and somatic symptom disorder: Comorbidity, correlates, and overlap with DSM-IV hypochondriasis. Journal of Psychosomatic Research 101, 31-7. [DOI:10.1016/j.jpsychores.2017.07.010] [PMID]

Pourhoseinzadeh, M., Gheibizadeh, M., \& Moradikalboland, M (2017). The relationship between health locus of control and health behaviors in emergency medicine personnel. International Journal of Community Based Nursing and Midwifery, 5(4) 397-407. [PMID] [PMCID]

Reuman, L., Jacoby, R. J., Blakey, S. M., Riemann, B. C., Leonard, R. C., \& Abramowitz, J. S. (2017). Predictors of illness anxiety symptoms in patients with obsessive compulsive disorder. Psychiatry Research, 256, 417-22. [DOI:10.1016/j.psychres.2017.07.012] [PMID]

Rosenbloom, T., \& Eldror, E. (2017). Perfectionism as a moderator of the association of Work Connectivity Behavior After-hours (WCBA) and burnout. North American Journal of Psychology, 19(2), 461-76. https://psycnet.apa.org/record/2017-24005-013

Seeliger, H., \& Harendza, S. (2017). Is perfect good? Dimensions of perfectionism in newly admitted medical students. BMC Medical Education, 17(1), 206. [DOI:10.1186/s12909-017-10349] [PMID] [PMCID]

Sharifi, H. P., Salehi, M., EmamiPour, S., \& Bashardoust, S. (2015). An Investigation into Psychometric Properties of Hill's Perfectionism Inventory. Journal of Modern Industrial/Organization Psychology, 2(7), 9-19. http:// psy.journals.iau-garmsar.ac.ir/ article_538721_5bb10073fad537b9b0223c9ea9651a79.pdf

Shumaker, E. A., \& Rodebaugh, T. L. (2009). Perfectionism and social anxiety: Rethinking the role of high standards. Journal of Behavior Therapy and Experimental Psychiatry, 40(3), 423-33. [DOI:10.1016/j.jbtep.2009.04.002] [PMID] [PMCID] 
Skidmore, J. R., Dyson, S. J., Kupper, A. E., \& Calabrese, D. (2014). Predicting illness behavior: health anxiety mediated by locus of control. American Journal of Health Behavior, 38(5), 699-707. [DOI:10.5993/AJHB.38.5.7] [PMID]

Soidla, K., \& Akkermann, K. (2020). Perfectionism and impulsivity based risk profiles in eating disorders. International Journal of Eating Disorders, 53(7), 1108-19. [DOI:10.1002/eat.23285] [PMID]

Stoeber, J., \& Childs, J. H. (2011). Perfectionism. In R. J. R. Levesque (ed), Encyclopedia of Adolescence. Berlin: Springer. [DOI:10.1007/978-1-4419-1695-2_279]

Taghavizade Ardakani, M., Akbari, B., Hossein Khanzade, A. A., \& Moshkbide Haghighi, M. (2019). [Comparing the effects of cognitive-behavioral therapy and acceptance and commitment therapy on the perfectionism of patients with obsessivecompulsive disorder (Persian)]. The Horizon of Medical Sciences, 26(1), 24-37. [DOI:10.32598/hms.26.1.3093.1]

Williams, S. E., Zahka, N. E., \& Kullgren, K. A. (2020). Somatic symptom and related disorders. In B. D. Carter, \& K. A. Kullgren (Eds.), Clinical Handbook of Psychological Consultation in Pediatric Medical Settings (pp. 169-81). Berlin: Springer International Publishing. [DOI:10.1007/978-3-030-35598-2_14]

Willis, C., \& Chalder, T. (2021). Concern for Covid-19 cough, fever and impact on mental health. What about risk of somatic symptom disorder? Journal of Mental Health, 30(5), 551-5. [DO I:10.1080/09638237.2021.1875418] [PMID] 
This Page Intentionally Left Blank 